\title{
Why do single event probabilities confuse patients?
}

\author{
Statements of frequency are better for communicating risk
}

\author{
Gerd Gigerenzer director, Mirta Galesic researcher \\ Centre for Adaptive Behaviour and Cognition, Max Planck Institute for Human Development, Berlin
}

The news reader announces a $30 \%$ chance of rain tomorrow. Thirty per cent of what? Most people in Berlin think that it will rain tomorrow $30 \%$ of the time: for seven or eight hours. ${ }^{1}$ Others believe that it will rain tomorrow in $30 \%$ of the region, so probably not where they live. In New York the majority believe that it will rain on $30 \%$ of the days for which the prediction was made. That is, most likely it won't rain tomorrow.

A chance of rain tomorrow is a single event probability. It refers to a unique event, such as rain tomorrow, and by definition does not specify a reference class. But people think in terms of classes: time, region, or days. These are not the only ones. As a woman in New York explained, "I know what 30\% means: three meteorologists think it will rain, and seven not."

It is often said that people cannot think in terms of probabilities. But the real problem here is professionals' risk communication. Using a frequency statement instead of a single event probability, meteorologists could state clearly that "it will rain on $30 \%$ of the days for which we make this prediction." New technologies have enabled meteorologists to add numerical precision to mere verbal statements ("it will be likely to rain tomorrow"), but little attention has been paid to the art of risk communication.

In healthcare the situation is similar. A psychiatrist used to prescribe fluoxetine to patients with depression. He always explained potential side effects, including loss of sexual interest and impotence: "If you take the medication, you have a 30-50\% chance of developing a sexual problem." ${ }^{, 2}$ When he finally realised that he was using a single event probability, he switched to a frequency statement, which automatically specifies a reference class: "Of 10 patients to whom I prescribe the drug, three to five report a sexual problem." Now patients were less anxious about taking it. How had they initially understood the "30-50\% chance"? Many had believed that something would go awry in 30-50\% of their sexual encounters. The psychiatrist thought of his patients as the reference class, but the patients thought about their own sex life. If you always look at the sunny side of life, "three to five patients out of 10" doesn't make you nervous, because you think those three to five are the others. But even the brightest optimists are in trouble if the same numbers refer to their own sexual encounters. As a consequence, willingness to take the drug is reduced.

The ambiguity of single event probabilities seems largely to have gone unnoticed. We could find only a single study in the medical risk literature. ${ }^{3}$ If the problem is largely one of risk communication, then the usual culprit, numeracy, should not matter much. We asked 117 young and 73 elderly adults in Berlin what is meant by a "30-50\% chance of developing a sexual problem," such as impotence or loss of sexual interest, after taking a popular drug for depression. Consistent with the ambiguity of the statement, people thought of different reference classes (table $\Downarrow$ ), with interpretations varying more widely among the older group. Although misunderstanding is typically attributed to innumeracy, the respondents' level of numeracy made next to no difference. The problem is in the art of communication, not simply in people's minds.

Using probabilities without specifying a reference class is widespread in communication of risk in healthcare. For instance, the Mayo Clinic announced: "The Food and Drug

Administration (FDA) says that an extensive analysis of clinical trials showed that antidepressants may cause or worsen suicidal thinking or behavior in children and adolescents. The analysis showed that children taking antidepressants had about a $4 \%$ chance of developing suicidal thoughts or behavior, compared with only a $2 \%$ chance in children taking a sugar pill (placebo)." What does it mean for a child to have a $4 \%$ chance of suicidal thoughts or behaviour? It remains unclear. Some parents might think that this occurs to $4 \%$ of children who take antidepressants, while others might believe that their child will have suicidal thoughts $4 \%$ of the time or that $4 \%$ of the pills are flawed and cause suicidal thoughts.

The US Centers for Disease Control and Prevention publicises that "condoms are $85-98 \%$ effective at preventing pregnancy."7 No reference class is specified on that page. A woman contemplating the use of condoms might think that:

a) she will get pregnant after $2-15 \%$ of times she has sex

b) $2-15 \%$ of women relying on condoms get pregnant

c) $2-15 \%$ of condoms are defective, or 
d) $2-15 \%$ of men don't know how to use a condom safely. Other websites make it clear that the effectiveness of birth control methods refers to "the number of women out of 100 who will have an unplanned pregnancy in the first year of using a method."

The official website of the US Prostate Cancer Institute reports that "men have a $40 \%$ to $90 \%$ chance of experiencing retrograde ejaculation after prostatectomy." "An ordinary man might think this estimate refers to the proportion of his sexual acts or to the proportion of men with prostatectomy where retrograde ejaculation occurs at least once - or to something else altogether. In sum, single event probabilities confuse patients because they do not specify a reference class. Good communication of risk requires a clear statement of what a probability refers to. Although necessary, this step alone is not sufficient, given that some patients misinterpret risks even when a reference class is given. ${ }^{10} \mathrm{With}$ the advance of personalised medicine and genetic counselling, doctors and patients will be overwhelmed by probabilities for individual patients. Frequency statements can help reduce potential confusion because they always refer to a class and are easily understood.

1 Gigerenzer G, Hertwig R, van den Broek E, Fasolo B, Katsikopoulos K. "A 30\% chance of rain tomorrow": how does the public understand probabilistic weather forecasts? Risk Analysis 2005;25:623-9.

2 Gigerenzer G. Reckoning with risk: learning to live with uncertainty. Penguin Books, 2002.

3 Slovic P, Monahan J, MacGregor DG. Violence risk assessment and risk communication: the effects of using actual cases, providing instruction, and employing probability versus frequency formats. Law and Human Behavior 2000;24:271-96.

4 Lipkus IM, Samsa G, Rimer BK. General performance on a numeracy scale among highly educated samples. Med Decis Making 2001;27:37-44.

5 Schwartz LM, Woloshin S, Black WC, Welch GH. The role of numeracy in understanding the benefit of screening mammography. Ann Int Med 1997;127:966-71.

6 Mayo Clinic. Antidepressants for children: explore the pros and cons. www.mayoclinic. com/health/antidepressants/MH00059.

7 Centers for Disease Control and Prevention. Unintended pregnancy prevention: contraception. www.cdc.gov/reproductivehealth/unintendedpregnancy/contraception.htm. eMedicineHealth. Effectiveness rate of birth control methods. www.emedicinehealth.com/ effectiveness_rate_of_birth_control_methods-health/article_em.htm.

9 Prostate.net. Prostate cancer treatment side effects. www.prostate.net/prostate-cancer/ treatment-of-prostate-cancer/prostate-cancer-treatment-side-effects.

10 Hanoch Y, Miron-Shatz T, Himmelstein M. Genetic testing and risk interpretation: how do women understand lifetime risk results? Judgment and Decision Making 2010;5:116-23.

Cite this as: BMJ 2012;344:e245

๑ BMJ Publishing Group Ltd 2012 


\section{Table}

Table 1 | Interpretations of " $\mathbf{3 0 - 5 0 \%}$ chance of developing a sexual problem" after taking a drug

\begin{tabular}{|c|c|c|c|c|}
\hline \multirow[b]{2}{*}{ Interpretation } & \multicolumn{2}{|c|}{$\%$ of respondents aged $18-35$ years $(n=117)$} & \multicolumn{2}{|c|}{$\%$ of respondents aged $60-77$ years $(n=73)$} \\
\hline & Low numeracy* $(n=43)$ & High numeracy ${ }^{\star}(n=74)$ & Low numeracy ${ }^{*}(n=52)$ & High numeracy $(n=21)$ \\
\hline $\begin{array}{l}\text { A: } 30-50 \% \text { of patients taking the drug will } \\
\text { have sexual problems }\end{array}$ & 65 & 78 & 33 & 38 \\
\hline $\begin{array}{l}\text { B: Patients taking the drug will have a } \\
\text { problem in } 30-50 \% \text { of their sexual encounters }\end{array}$ & 9 & 8 & 33 & 33 \\
\hline $\begin{array}{l}\text { C: Patients taking the drug will find sexual } \\
\text { intercourse to be } 30-50 \% \text { less enjoyable than } \\
\text { usual }\end{array}$ & 12 & 6 & 21 & 10 \\
\hline D: Something else & 14 & 8 & 13 & 19 \\
\hline
\end{tabular}

* Numeracy defined as high or low according to median split across both groups on a numeracy rating consisting of the 12 items from Lipkus et al and Schwartz et al. $^{45}$ 